\title{
The Additional Value of Cystoscopy with Urodynamic Study in the Assessment of Patients with Urinary Incontinence
}

\author{
Diar Hameed Bajalan', Sarwar Noori Mahmood1, Ismaeel Hama Ameen', \\ Zhino Noori Hussain ${ }^{2}$ \\ ${ }^{1}$ Department of Surgery, School of Medicine, University of Sulaimania, Sulaymaniyah, Iraq \\ ${ }^{2}$ Department of Urology, Sulaymaniyah Surgical Teaching Hospital, Sulaymaniyah, Iraq \\ Email:diardjn@yahoo.com,sarwar.mahmood@univsul.edu.iq
}

Received 12 May 2016; accepted 10 July 2016; published 13 July 2016

Copyright (C) 2016 by authors and Scientific Research Publishing Inc.

This work is licensed under the Creative Commons Attribution International License (CC BY). http://creativecommons.org/licenses/by/4.0/

(c) (i) Open Access

\begin{abstract}
Background: Urinary incontinence (UI) is generally defined as the involuntary loss of urine from the bladder through the urethral meatus. Filling cystometry is the method by which the pressure/ volume relationship of the bladder is measured during bladder filling. Purpose: To determine the value of diagnostic cystoscopy in addition to Urodynamic study (UDS) in patients with primary urinary incontinence. Material and Methods: 200 patients with primary incontinence studied prospectively from January 2013 to June 2014. Their age ranges from (14 - 93 years), 86.5\% were female, and $13.5 \%$ of them were male. In addition to physical, neurological examination and biochemical investigations, urine analysis and urine culture with Ultra-sound and Post void residual volume (PVRV), all patients underwent diagnosticflexible cystoscopy under local anesthesia, and urodynamic study. Result: $43.5 \%$ of patients age were between (34 - 53 years), (39\%) between (54 73 years), (9\%) between (14 - 33 years) and $(8.5 \%)$ were between ( 74 - 93 years). Atonic bladder on UDS were (40.5\%), Detrusor over activity $(29 \%)$, patients with normal UDS were $(22 \%)$ and patients that had DSD (Detrusor Sphincter Dyssynergia) were (8.5\%). Eighty-four cases (42\%) were found to have normal cystoscopy, those with grade-I-II bladder wall trabeculations were $(49 \%)$ and patients with grade-III were $(8.5 \%)$. Sixty-one patients $(30.5 \%)$ with normal diagnostic cystoscopy have abnormal UDS (Atonic bladder, over-active bladder and DSD) while twenty-one (10.5\%) patients with normal UDS had bladder wall trabeculations (grade-I-III) on diagnostic cystoscopy. Conclusion: Diagnostic cystoscopy in addition to urodynamic study will put in further knowledge in the assessment of patients with urinary incontinence. To some extent, it can predict the diagnosis.
\end{abstract}

\section{Keywords}

Urodynamic Study, Diagnostic Cystoscopy, Incontinence

How to cite this paper: Bajalan, D.H., Mahmood, S.N., Ameen, I.H. and Hussain, Z.N. (2016) The Additional Value of Cystoscopy with Urodynamic Study in the Assessment of Patients with Urinary Incontinence. Open Journal of Urology, 6, 109113. http://dx.doi.org/10.4236/oju.2016.67019 


\section{Introduction}

The basic factors of normal bladder function are bladder capacity, accommodation, sensation, contractility, voluntary control, and response to drugs. All these can be evaluated by cystometry [1]. Bladder filling and urine storage require: accommodation of increasing volumes of urine at a low intravesical pressure (normal compliance) and with appropriate sensation, a bladder outlet that is closed at rest and remains so during increased intra-abdominal pressure and absence of involuntary bladder contractions [2]. The distended bladder is normally quite smooth, with hypertrophy; individual muscle bundles become taut and give a coarsely interwoven appearance to the mucosal surface known as (Trabeculation) of bladder wall [3]. When bladder passes through the stages of irritability, compensation, and decompensation outlet obstruction may occur in response to outlet resistance, hypertrophy of detrusor muscles begins and trabeculations may develop [4].

Normal intravesical pressure is about $30 \mathrm{~cm}$ of water at the beginning of micturition. The Trabeculated (hypertrophied) bladder may reach pressures 2 - 4 times as great in its attempt to force urine past the obstruction [3]. The bladder wall trabeculationsis classified into four grades according to maximum depth of bladder surface: Grade 0 (none), Grade 1 (mild, depth $<5 \mathrm{~mm}$ ), Grade 2 (moderate, depth 5 - $10 \mathrm{~mm}$ ), and Grade 3 (severe, depth $>10 \mathrm{~mm})[5]$.

Urinary incontinence (UI) is generally defined as the involuntary loss of urine from the bladder through the urethral meatus [6]. The condition of (UI) is far more prevalent in women than men with a significant progress in incidence with the increase of age [7].

Urodynamic study (UDS) is the term used to describe testing and measurements of the function of the lower urinary tract. It is clear that a number of conditions and diseases affect the lower urinary tract and disrupt the storage and/or evacuation of urine. Functional abnormalities of the lower urinary tract can be divided into the following: Storage dysfunction, Emptying dysfunction and combined dysfunction [8]. The aim of UDS is to reproduce the troublesome symptoms, answer specific clinical questions, establish a precise diagnosis, determine the severity of the condition and plan further investigations or therapies [9]. The pre-urodynamic assessment comprises: A focused history and physical examination, urinalysis with or without culture, a 24-hour pad test (for patients with incontinence), Uroflow and estimation of PVR urine [4].

The aim is to determine the additional value of diagnostic cystoscopy to UDS in the assessment of incontinence.

\section{Patients and Methods}

Two hundred patients presented with urinary incontinence studied prospectively between January 2013 and June 2014. Full history, physical (digital rectal examination; in male patients and abdominal examination), neurological examination (perineal sensations and cavernoso-anal reflex examination) were done. Full blood count and biochemistry, urinalysis with urine culture were done. Also all patients underwent ultrasonography of urinary tract and post void residual urine volume. In addition, all underwent flexible cystoscopy under local anesthesia. Urodynamic study done by (ANDROMEDA medizinische System GmbH 2002; device made in Germany) including Flowmetry, Cystometry, Pressure flow-study and UPP were performed. They were prepared by bowel and by prophylactic antibiotics. Patients with diabetes mellitus, neurological diseases, secondary incontinence were excluded.

\section{Results}

Two hundred patients with primary mixed urinary incontinence were analyzed, 173 cases (86.5\%) of them were female and 27 (13.5\%) were male (Table 1). Eighteen patients (9\%) ages were (14 - 33 years), 87 cases (43.5\%) were between (34 - 53 years), 78 cases (39\%) were between (54 - 73 years) and 17 cases (8.5\%) were between (74 - 93 years) as in (Table 2).

Eighty four patients (42\%) have normal diagnostic cystoscopy, 99 cases (49.5\%) had grade one (mild) to grade two (moderate) trabeculations of bladder wall and 17 cases (8.5\%) had grade three (severe) bladder wall trabeculation (Table 3).

Forty four patients (22\%) have normal urodynamic study, 81 cases (40.5\%) had hypotonic bladder, 58 cases (29\%) had detrusor over activity and 17 cases (8.5\%) had DSD as shown in (Table 4).

Twenty three patients (11.5\%) had normal both diagnostic cystoscopy with UDS and 21 cases (10.5\%) had normal UDS with grade (I to II) trabeculations on diagnostic cystoscopy. P-value is (0.00) statistically significant. 
Table 1. Shows frequency of gender in all patients.

\begin{tabular}{ccc}
\hline & Frequency & $\%$ \\
\hline Male & 27 & 13.5 \\
Female & 173 & 86.5 \\
Total & 200 & 100 \\
\hline
\end{tabular}

Table 2. Shows frequency of age in all patients.

\begin{tabular}{ccc}
\hline Age & Frequency & $\%$ \\
\hline $14-33$ years & 18 & 9 \\
$34-53$ years & 87 & 43.5 \\
$54-73$ years & 78 & 39 \\
$74-93$ years & 17 & 8.5 \\
Total & 200 & 100 \\
\hline
\end{tabular}

Table 3. Shows frequency of Diagnostic cystoscopy results in all patients.

\begin{tabular}{ccc}
\hline Class & Frequency & $\%$ \\
\hline Normal & 84 & 42 \\
Grade I-Grade II trabeculation & 99 & 49.5 \\
Grade III trabeculation & 17 & 8.5 \\
Total & 200 & 100 \\
\hline
\end{tabular}

Table 4. Shows frequency of Urodynamic study results in all patients.

\begin{tabular}{ccc}
\hline Class & Frequency & $\%$ \\
\hline Normal & 44 & 22 \\
Atonic bladder & 81 & 40.5 \\
Detrusor over activity & 58 & 29 \\
DSD & 17 & 8.5 \\
Total & 200 & 100 \\
\hline
\end{tabular}

Atonic bladder on UDS were 81 cases in which 39 cases (19.5\%) of them had normal diagnostic cystoscopy, 38 cases (19\%) had grade (I to II) bladder wall trabeculation and 4 cases (2\%) had grade III bladder wall trabeculation on diagnostic cystoscopy. P-value is $(0.00)$ statistically significant.

Those with detrusor over activity on UDS were 58 cases; 17 cases (8.5\%) of them had normal diagnostic cystoscopy, 31 cases (15.5\%) had grade (I to II) trabeculation and 10 cases (5\%) had grade III bladder wall trabeculationon diagnostic cystoscopy. P-value is $(0.00)$ statistically significant.

Those with DSD on UDS were 17 patients in which 5 cases (2.5\%) show normal diagnostic cystoscopy, 9 cases (4.5\%) had grade (I to II) trabeculation and 3 cases (1.5\%) had grade III bladder wall trabeculation by diagnostic cystoscopy. P-value is (0.00) statistically significant (Table 5).

Those with normal diagnostic cystoscopy were 84 cases (42\%) in which 23 (11.5\%) of them had normal UDS while 51 cases $(25.5 \%)$ had abnormal UDS.

Those with grade (I to II) bladder wall trabeculations on cystoscopy were 99 cases (49.5\%) in which 21 of them had normal UDS and the other 78 cases (39\%) had abnormal UDS.

Those with grade III bladder wall trabeculation on cystoscopy were 17 cases (8.5\%); all of them had abnormal UDS.

Results were calculated by using Stat graphic Info program which is a public domain statistical software for 
Table 5. Shows cross relation between cystoscopy \& urodynamic study in all patients.

\begin{tabular}{|c|c|c|c|c|c|c|}
\hline & & & Cystoscopy & & & P-value \\
\hline \multirow{6}{*}{ 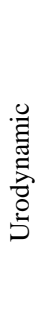 } & & Normal & $\begin{array}{l}\text { Mild-Moderate } \\
\text { trabeculation }\end{array}$ & $\begin{array}{c}\text { Severe } \\
\text { trabeculation }\end{array}$ & Total & \\
\hline & Normal & 23 & 21 & 0 & 44 & 0.00 \\
\hline & Atonic bladder & 39 & 38 & 4 & 81 & 0.00 \\
\hline & Detrusor over activity & 17 & 31 & 10 & 58 & 0.00 \\
\hline & DSD & 5 & 9 & 3 & 17 & 0.00 \\
\hline & Total & 84 & 99 & 17 & 200 & \\
\hline
\end{tabular}

epidemiology and statistical package for social science \{version 5:1\} and a P-value of equal and less than 0.01 was considered as significant.

\section{Discussion}

Cystourethroscopy facilitates anatomical assessment of the bladder and the urethra. On the other hand, cystoscopy helps detect bladder lesions and identify other pathologies. These may include foreign bodies (eg, suture and mesh material from prior surgery for prolapse or incontinence), bladder cancer, and bladder stones conditions that would otherwise remain undiagnosed if only urodynamic studies are performed [10].

Majority of our patients were female (86.5\%), $43.5 \%$ of patients age were between (34 - 53) years. (40.5\%) presented with Atonic bladder as a UDS finding, so most have hypotonic or atonic bladders.

Eighty four cases (42\%) had normal Cystoscopic finding, 44 cases (22\%) had normal UDS finding, those with normal cystoscopy and abnormal UDS were 61 cases (30.5\%) so about one third of the patients had no Cystoscopic features which suggest or predict the UDS diagnosis, and among cases with normal UDS associated with bladder wall trabeculations were 21 cases (10.5\%).

Majority of our patients age were between (34 - 53 years), this is different from a study done by reynard et al. which reported that incontinence more in elderly [11]. This difference might be due to sample collection or earlier presentations of our patients. Zimmern et al. reported that incontinent patients were mostly in elderly, suggested that detrusor contractility and efficiency decrease with age while our study showed that elderly patients present to a lesser extend to the urologist [12].

Shuang Wei-bing et al. have shown that bladder trabeculations as a kind of morphology change has matched well with the detrusor function change and Urethrocystoscopy provides good information on the site, patency of bladder neck and severity of bladder obstruction [13].

In our study there were statistically significant correlation between incontinence and bladder wall trabeculations; this is compatible with a study done by Yoo Jin Lee at al [14], Shuang Wei-bing et al. [13] K. Ezzeldin et al. [15]. That had shown a significant correlation between bladder trabeculations and urinary incontinence Also Liang CC et al. which reported that patients with bladder trabeculations had higher incidence of incontinence [16].

\section{Conclusion}

In patients presented with urinary incontinence who are scheduled to have urodynamic study, diagnostic cystoscopy is recommended. Performing it together with urodynamic study, further information will add to the final study results of UDS. Additionally it can, to some extent predict the diagnosis.

\section{References}

[1] Tanagho, E.A., Deng, D.Y. and Jack, W. (2008) Urodynamic Studies, Smith’s General Urology. 17th Edition, 460-461.

[2] Wein, A.J. (2012) Pathophysiology and Classification of Lower Urinary Tract Dysfunction, Campbell-Walsh Urology. 10th Edition, Saunders, Philadelphia, 61.

[3] Tanagho, E.A. (2008) Urinary Obstruction, Smith’s General Urology. 17th Edition, 167.

[4] Blavias, J., Chancellor, M., Weiss, J., et al. (2007) Pre Urodynamic Evaluation, Atlas of Urodynamics. 2nd Edition, 
3-4.

[5] Cho, S.Y., Bae, J., Yoo, C. and Oh, S.J. (2013) Establishment of a Grading System for Bladder Trabeculation. Department of Urology, SMG-SNU Boramae Medical Center, Seoul, 503-507.

[6] Potts, J.M., Rackly, R.R. and Abdelmalak, J.B. (2004) Management of Female Urinary Incontinence a Guide to Clinical Practice. Essential Urology, 153-154.

[7] Thüroff, P., Abrams, K.E., Andersson, W., Artibani, E., et al. (2014) Guidelines on Urinary Incintinence. European Association of Urology, 3.

[8] Nitti, V.W. (2012) Urodynamics and Video-Urodynamic Evaluation the Lower Urinary Tract. Campbell-Walsh Urology, 10th Edition, 1847-1855.

[9] Chapple, C.R., MacDiarmid, S.A. and Patel, A. (2009) Urodynamics Made Easy. 3rd Edition, 21.

[10] Gill, B.C., Kim, E.D., et al. (2015) Cystoscopy and Urethroscopy in the Assessment of Urinary Incontinence. http://emedicine.medscape.com/article/1988620-overview

[11] Reynard, J., Brewster, S. and Biers, S. (2009) Incontinence. Oxford Handbook of Urology, 2nd Edition, 126.

[12] Zimmern, P., Litman, H.J., Nager, C.W., et al. (2014) Effect of Aging on Storage \& Voiding Function in Women with Stress Predominant Urinary Incontinence. Journal of Urology, 192, 464-468. http://dx.doi.org/10.1016/j.juro.2014.01.092

[13] Shuang, W.-B., Liu, Q. and Wang, D.-W. (2010) Relationship between the Bladder Trabeculation Grades \& Pressure of Detrusor in BPH. China Journal of Modern Medicine.

[14] Lee, Y.J., Kim, S.R., Kim, S.K. and Bai, S.W. (2014) The Significance and Factor Related to Bladder Outlet Obstruction in Pelvic Floor Dysfunction in Operative Urodynamic Studies. Obstetrics \& Gynecology Science, 57, 59-65.

[15] Ezzeldin, K., de Wildt, M.J.A.M., Rosier, P.F.W.M., et al. (1996) The Correlation between Urodynamic \& Cystoscopy Finding in Elderly Men with Voiding Complaints. The Journal of Urology, 155, 1018-1022.

[16] Liang, C.C., Chang, Y.L., Lin, Y.H. and Chang, S.D. (2013) Significance of Bladder Trabeculation in Postmenopausal Women with Severe Pelvic Organ Prolapse: Clinical Urodynamic Assessment. Menopause, 20, 813-817.

\section{Submit or recommend next manuscript to SCIRP and we will provide best service for you:}

Accepting pre-submission inquiries through Email, Facebook, Linkedin, Twitter, etc A wide selection of journals (inclusive of 9 subjects, more than 200 journals)

Providing a 24-hour high-quality service

User-friendly online submission system

Fair and swift peer-review system

Efficient typesetting and proofreading procedure

Display of the result of downloads and visits, as well as the number of cited articles

Maximum dissemination of your research work

Submit your manuscript at: http://papersubmission.scirp.org/ 